\title{
Psycholinguistic conditions in vocabulary acquisition
}

\author{
Egamberdieva Shakhzoda Damirovna ${ }^{1}$, Egamberdieva Farida Oktamovna ${ }^{2}$, Egamberdiev \\ Khumoyun $^{3}$, Ergasheva Yulduz ${ }^{4}$ \\ ${ }^{1}$ Linguistics (English), National University, Tashkent, Uzbekistan. \\ ${ }^{2}$ Journalism, National University, Tashkent, Uzbekistan. \\ ${ }^{3}$ Theory of economics, National University, Tashkent, Uzbekistan. \\ ${ }^{4}$ Natural Geography, National University, Tashkent, Uzbekistan.
}

farida_6767@mail.ru

\begin{abstract}
Present article examines the psycholinguistic factors that affect ease of learning foreign language vocabulary acquisition. Demonstrate the orthographic and phonological patterns of vocabulary acquisition.
\end{abstract}

Keywords: Psycholinguistic factors, foreign language (FL), vocabulary acquisition, pronounceableness, articulatory feature, keyword mediator.

\section{INTRODUCTION}

Many factors might affect the ease of foreign language (FL) vocabulary acquisition. In essence, the process of learning a FL word is to map a novel sound pattern (which will be variable across speakers, dialects, emphases, etc.) to a particular semantic field that may (or may not) have an exact equivalent in the native language. Even this rudimentary description implicates a range of relevant variables: pronounceableness, familiarity with semantic content, and clear labeling of that meaning in the native language. We will briefly review established findings concerning such psycholinguistic variables before describing a study that assesses their effects on vocabulary learning.

\section{MATERIALS AND METHODS}

Clearly, novice language learners are bound up in the orthographic and phonological aspects of vocabulary. While native speakers' lexical entries are clustered semantically (as evidenced by free associations of the type top-snow->hill->valley, etc., learners often make associations driven by orthographic or phonological confusion, for example, artist (confusion with actor) or academic(confusion with academician) or biscuit(confusion with sponge cake) or brilliant(confusion with diamond), etc. Similarly, G.Henning demonstrated that in a vocabulary recognition task, more-advanced learners and native speakers made errors indicating semantic clustering of lexical items whereas less-advanced learners showed evidence of a predominance of acoustic rather than semantic clustering [1].

Three or four dozen different independent gestures of the articulatory apparatus play distinctive roles in human speech [2]. Different languages make use of different ranges of articulatory features. Thus difficulty arises when the FL learner is faced with features not exploited in the native language. For example, the contrast between [0] and [p] sounds in English pronunciation differentiates not always in the process of phonetic acquisition. This contrast is not exploited in Uzbek and thus Uzbek learners of English must (a) learn to identify these unfamiliar features to perceive speech and (b) develop new motor patterns to accurately reproduce these in their own speech. This leads to predictions at both language and word levels:

1. The less the overlap between the feature set of the native and the foreign language, the harder it will be for the FL learner to learn to speak that language. 
2. The less the overlap between the feature set of the native and the foreign word, the harder it will be for the FL learner to learn that word. Thus, for example, an Uzbek student of English has much more difficulty with the words think, these, father, etc.

The pronounceableness of a word is determined not only by its phonemes and their articulatory features, but also by their position in a spoken word. Both absolute and relative position are important. An example of absolute position is [ $\mathrm{y}]$ (the ng sound), which is common in English at the end of words but never occurs at the beginning.

Recent work in cognitive psychology suggests that individual differences in ability to repeat novel phonological patterns (phonological short-term memory span) play a part in determining long-term vocabulary acquisition. S.Gathercole and A.Baddeley demonstrated in a longitudinal study that 5-year-old children's native receptive vocabulary acquisition was predicted by their short-term phonological memory ability (assessed by non word repetition) one year earlier They concluded that not only word length but also phonological structure are important determinants of ease of repetition of novel words. This is a "linguistic hypothesis," whereby the familiarity of a novel word's phonological structure determines its repetition accuracy, with phonological frames constructed from similar vocabulary entries in the learner's lexicon being used to support the temporary phonological representation. Whereas these conclusions accord with our theoretical perspective, it is unfortunate that they go beyond their data - the method used by S.Gathercole et al. to assess phonological familiarity was to have undergraduates rate the word likeness of the nonwords on a dimension of very like a word to not like a word at all, a task that potentially confounds many dimensions of similarity, with the raters'judgments open to a variety of orthographic, phonological, and semantic factors [3].

Moreover, items of experience are classified differently by different languages. The class corresponding to one word and one thought in Language A may be represented by Language B as two or more classes corresponding to two or more words and thoughts. Thus, for example, A.Desrochers and I.Begg refer to the French distinction between balle-a spherical object that can be caught with one hand, and ballon-that requiring both hands; the English translation ball is insufficient to represent and distinguish these meanings. Terms for color, temperature, divisions of the day, kinship, and parts of the body are all semantic fields that are divided up in different ways in different languages [4]. Navajo has a fourth person singular and plural, which is used to address someone in the room or within earshot without naming him or her directly, and many African languages have inclusive and exclusive forms of the first person plural (we, including you to whom I am speaking vs. we, not including you to whom I am speaking). Hopi has one noun that covers everything that flies, with the exception of birds-Hopi Indians call insect, plane, and aviator all by the same word and feel no difficulty about it. These few examples demonstrate the phenomenon of linguistic relativity [5]. In this case we can also give the example of difficulties of vocabulary acquisition by Uzbek students when, for example, there are no specific words that are called realia, or exotic words, which do not exist in their native language as there are no such objects, like soda fountain, vanilla milk, bread lines, and many others.

Therefore, learning a new FL word is going to be easy if there is a mapping of meanings represented by the native and foreign words. It is going to be harder if the same conceptual fields are covered by different lexical fields in different languages. Some researches demonstrated that even advanced adult ESL learners differed substantially from native speakers in the semantic boundaries that they ascribed to English spatial prepositions, with word usage being heavily influenced by native language transfer [6].

Meanwhile, R.Atkinson and M.Raugh reported an experiment in which they compared learning of FL vocabulary by means of mnemonics with a control condition in which participants used their own strategies. In the experimental condition, participants were presented with a Russian word and its English translation together with a word or phrase in English that sounded like the Russian word. For example, the Russian word for battleship is linkor. American students were asked to use the word Lincoln, called the keyword, to help them remember this. R.Atkinson and M.Raugh found that people who had used the keyword method learned substantially more English translations of Russian words than did the control group and that this advantage was maintained up to six weeks later.

\section{DISCUSSION}

The common explanation for the success of these systems is that the keyword enables people to combine in a single associative image the referent of one native word with that of a second native word that sounds like the foreign word, that is, the meanings of the native word and the keyword are integrated in one image. There are two stages in recall using keywords. The first stage of recalling the meaning of a foreign word involves remembering the native keyword that sounds like the foreign word. The second stage involves accessing an interactive image containing the referent ofthe keyword and "seeing" the object with which it is associated. By naming this object the learner accesses the native translation. 
The involvement of keyword mediators introduces a number of additional potential psycholinguistic determinants of success:

1. Reminding power of foreign word for keyword. The first of M.Raugh and R.Atkinson's criteria for a good keyword is that it sounds as much as possible like a part (not necessarily all) of the foreign word. Whereas it may be relatively easy to find English keywords that sound like some foreign words (e.g., for the English words social, intellect, international, planet), others are considerably more problematical. M.Raugh and R.Atkinson demonstrate a correlation of 53 between the probability of a keyword being remembered given a Russian word and the probability of the English translation being remembered by different subjects using the same keyword as a mnemonic.

2. Reminding power of keyword for foreign word. M.Raugh and R.Atkinson's criterion applies here, too, but with even more importance because the keyword has to cue the pronunciation of the foreign word. So it has to sound as close as possible to the foreign word. Word recall is likely to be best if the keyword or part of it overlaps with the initial part or cluster of the foreign word to be recalled. But it remains to be determined whether the best overlap is in terms of pronunciation or orthography or both.

3. Imageability of keyword. M.Raugh and R.Atkinson'ssecond criterion is that "it is easy to form a memorable imagery link connecting the keyword and the English translation". Thus "concrete nouns may be good as keywords because they are generally easy to image; abstract nouns for which symbolic imagery comes readily to mind also may be effective keywords" [7].

\section{RESULT}

Although many of these variables have been studied individually, their interrelationships remain to be determined. Furthermore, it is quite possible that each will make a different contribution depending on the learning strategy that students adopt - for example, repetition learners versus key-word learners.

\section{CONCLUSION}

In this way, the following effects and therefore their interactions on the "learnability" of FL vocabulary seem to be considerable:

1. Phonological content of the foreign word and the degree to which its phono tactic sequence accords with those found in the native language;

2. Word class;

3. Image ability of the concept;

4. Foreign and native word lengths; and

5. Orthographic content of the foreign word and the degree to which its phono tactic sequence accords with those found in the native language.

6. It further investigated whether, when subjects are instructed to use keyword mediation, the following factors play a determining role on FL learnability:

7. Whether the keyword is a noun or a verb;

8. The image ability of the keyword;

9. The image ability of the whole mediational sentence;

10. The spoken overlap between the keyword and the foreign word;

11. The orthographic overlap between the keyword and the foreign word; and

12. The degree to which the keyword reminds people of the foreign word.

\section{REFERENCES}

1. Henning G. H. Remembering foreign language vocabulary: Acoustic and semantic parameters. // Language Learning, 23, 1974, 185-196.

2. Wang W.S.-Y. The basis of speech. // Reed C.E. (Ed.) The learning of language. - New York: Appleton-Century-Crofts, 1971, 89-105.

3. Gatherole S.E., Willis C., Emslie, H., \&Baddeley, A.D. The influences of number of syllables and wordlikeness on children's repetition of nonwords. // Applied Psycholinguistics, 12, 1991, 349367.

4. Carter R., \& McCarthy M. Vocabulary and language teaching. - London: Longman, 1988.

5. Carroll J. B. (Ed.) Language, thought and reality: Selected writings of Benjamin Lee Whorf. Cambridge, Massachusetts: MIT Press, 1956.

6. Ijaz I. H. Linguistic and cognitive determinants of lexical acquisition in a second language. // Language Learning, 36. 1986, 401-451.

7. Paivio A., Desrochers A. Mnemonic techniques in second language learning. Journal of Educational Psychology, 73.1981, 780-795. 